Check for updates

Cite this: RSC Adv., 2017, 7, 32126

Received 28th April 2017

Accepted 16th June 2017

DOI: $10.1039 / c 7 r a 04774 f$

rsc.li/rsc-advances

\section{A graphene-based porous carbon material as a stationary phase for gas chromatographic separations}

\begin{abstract}
Xiaohong Yang, Changxia Li, Meiling Qi (D)* and Liangti Qu (D)*
This work presents the separation performance of a 3D graphene-based porous carbon material (GPCM) as a new stationary phase for capillary gas chromatography (GC). The statically coated GPCM column showed a column efficiency of 3210 plates per $\mathrm{m}$ and weak polar nature. Its resolving capability and retention behaviours were investigated by using structural and positional isomers and a complex mixture covering analytes of diverse types. The GPCM column exhibits high resolution for nonpolar to polar isomers and analytes of wide ranging variety. It also displays a different retention mechanism from the commercial polysiloxane column, showing preferential retention of alcohols, aromatics and halogenated compounds. In addition, the GPCM column exhibited good column repeatability and reproducibility with RSD values on retention times in the range of $0.01-0.03 \%$ for intra-day, $0.06-0.36 \%$ for inter-day and $0.44-2.1 \%$ for between-column, respectively. The advantageous separation performance shows the good potential of the GPCM stationary phase for GC analysis.
\end{abstract}

\section{Introduction}

Porous carbon materials (PCMs) have high specific surface area, hierarchical porous structures and physicochemical properties such as electric conductivity, thermal conductivity, chemical stability and low density and have attracted broad attention in a variety of fields such as catalyst supports, adsorbents and electrode materials. ${ }^{1,2}$ In separation science, PCMs have been reported as stationary phases for liquid chromatography ${ }^{3,4}$ and as adsorbents for benzene ${ }^{5}$ and dye $^{6}$ removal and carbon dioxide separation. ${ }^{7}$ Their preparation has been investigated regarding the effect of the nature of the templates, carbon sources/precursors and carbonization conditions. ${ }^{\mathbf{1 , 2}}$ Recently, using a metal-organic framework (MOF) as a template has gained wide research attention. ${ }^{\mathbf{1 , 8 - 1 3}}$ A new graphene-based PCM (denoted as GPCM in the following) ${ }^{12}$ was obtained by preparation of a three-dimensional (3D) graphene-MOF composite followed by thermal carbonization to decompose the MOFs and leave 3D GPCM behind. The as-fabricated GPCM possesses a hierarchical nanoporous structure with the improved surface area and chemical/thermal stability. In addition, it was doped with $3.4 \%$ nitrogen originating from the 2-methylimidazole (MeIm) in ZIF-8 (ZIF = zeolitic imidazolate framework).

Over the recent years, graphene-based materials have shown promise in separation science. Currently, they are mostly

Key Laboratory of Cluster Science, Ministry of Education of China, Beijing Key Laboratory of Photoelectronic/Electrophotonic Conversion Materials, School of Chemistry and Chemical Engineering, Beijing Institute of Technology, Beijing, 100081, China.E-mail: mlqi@bit.edu.cn; lqu@bit.edu.cn investigated as adsorbents for sample enrichment, ${ }^{\mathbf{1 4 - 1 7}}$ but their potential as stationary phase in gas chromatography (GC) $)^{18-21}$ and liquid chromatography ${ }^{22,23}$ is not well explored. Particularly, their separation capability for analytes of high resemblance such as structural/positional isomers is rarely reported, ${ }^{20}$ which is a challenging task that essentially requires a highly selective stationary phase to fulfill. As previously reported, 3D graphene ${ }^{19,20}$ and its composite with MOF $^{21}$ showed good GC separation performance of various types of organic analytes. Different from the reported graphene materials, the GPCM described above has hierarchical nanoporous structure doped with nitrogen. The basic 3D graphene structure may maintain its GC selectivity and hierarchical nanopores may facilitate quick mass transfer and diffusion of analytes in a chromatographic process. These features endow GPCM a promising candidate as GC stationary phase. It could be expected that GPCM may achieve high resolving capability for analytes of interest in short run time, which is quite worth exploration. To the best of our knowledge, however, the graphene-based porous materials have not been reported as stationary phases so far.

Herein, we present the investigation of the GPCM for its GC separation performance. After statically coated onto a fusedsilica capillary column, the GPCM column was investigated for its column efficiency, polarity, separation performance and column repeatability and thermal stability. Its separation performance was evaluated with respect to its selectivity, resolving capability and chromatographic retention behaviors for nonpolar to polar isomers including alkanes, alcohols and phenols. In addition, its comprehensive resolving ability and retention behaviours for a wide range of analytes covering 
alkanes, alcohols, esters, aldehydes, halogenated and aromatic compounds was also evaluated by a more complex mixture in comparison with 5\% phenyl methylpolysiloxane phase. This work demonstrates the great potential of the GPCM as a new GC stationary phase and also provides a research basis for applying diverse types of GPCMs as stationary phases in this field.

\section{Experimental}

\subsection{Materials and equipment}

All the chemicals used in this work were of analytical grade. Benzene, 2-pentanone, pyridine, 1-butanol and 1-nitropropane were purchased from Alfa Chemical Co., Ltd (Tianjin, China). $n$ Heptane, n-octane, 2,2,3-trimethylbutane, 2,2,4-trimethylpentane, 2,3-dimethylpentane, 2,2-dimethylhexane and 3methylheptane were purchased from Beijing Chemical Reagent Company (Beijing, China). The rest of the chemicals were purchased from Aladdin Chemistry Co. Ltd. (Shanghai, China). Untreated fused-silica capillary tubing $(0.25 \mathrm{~mm}$ i.d.) was purchased from Yongnian Ruifeng Chromatogram Apparatus Co. Ltd. (Hebei, China). A commercial HP-5MS capillary column $(10 \mathrm{~m} \times 0.25 \mathrm{~mm}$, i.d., film thickness $0.25 \mathrm{~m})$ coated with $5 \%$ phenyl methylpolysiloxane from Agilent Technologies Co. Ltd. (Palo Alto, CA, USA) was employed for reference.

An Agilent 7890A gas chromatograph (Palo Alto, CA, USA) equipped with a split/splitless injector, a flame ionization detector (FID) and an autosampler was used for GC separations. All the separations were performed under the following GC conditions unless otherwise specified: nitrogen of high purity $(99.999 \%)$ as carrier gas at a flow rate of $1 \mathrm{~mL} \mathrm{~min}^{-1}$, injection port at $250{ }^{\circ} \mathrm{C}$, split injection mode at a split ratio of $50: 1$ and FID as detector at $300{ }^{\circ} \mathrm{C}$. Temperature programs for the separations were provided under the figure legends. Thermogravimetric analysis (TGA) was performed on a DTG-60AH Thermogravimetric Analyzer (Shimadzu, Tokyo) from $30{ }^{\circ} \mathrm{C}$ to $800{ }^{\circ} \mathrm{C}$ at a ramp rate of $10{ }^{\circ} \mathrm{C} \mathrm{min}^{-1}$ under nitrogen atmosphere. The scanning electron microscopy (SEM) micrographs were recorded on a Hitachi S4800 microscope (Tokyo, Japan).

\subsection{Synthesis and characterization of the GPCM stationary phase}

The 3D graphene-based N-doped porous carbon material (GPCM) was synthesized and characterized by the methods described in our previous work. ${ }^{12}$ First, 3D graphene was prepared by hydrothermal reduction of graphene oxide (GO) aqueous dispersion. Briefly, $15 \mathrm{~mL}$ GO aqueous dispersion ( $2 \mathrm{mg} \mathrm{mL}^{-1}$ ) was sealed in a $25 \mathrm{~mL}$ Teflonlined autoclave. After heating at $180{ }^{\circ} \mathrm{C}$ for several hours, the autoclave was cooled down to room temperature and then the $3 \mathrm{D}$ graphene was obtained by freeze-drying. Afterwards, the 3D graphene sheets were soaked with methanol solution of $\mathrm{Zn}^{2+}$ ion and then placed in a ligand solution of 2-methylimidazole (MeIm). Upon molecules diffusion and solvothermal growth, uniform deposition of ZIF-8 crystals on 3D graphene sheets can be obtained. Afterwards, the prepared G-ZIF8 were transferred into a temperature programmed furnace under an Ar flow and were heat-treated at
$800{ }^{\circ} \mathrm{C}$ for $4 \mathrm{~h}$ at a heating rate of $3{ }^{\circ} \mathrm{C} \min ^{-1}$ for carbonization. After the materials were cooled to the room temperature, the resultant black lumps were collected and then washed with $\mathrm{HCl}$ aqueous solution. Finally, the carbonized sample was rinsed with a copious amount of distilled water and freeze-dried, and then the GPCM product was obtained.

\subsection{Fabrication of the GPCM capillary column}

A GPCM capillary column $(10 \mathrm{~m} \times 0.25 \mathrm{~mm}$, i.d. $)$ was prepared by static coating method. Prior to coating, the column was purged with nitrogen at $200{ }^{\circ} \mathrm{C}$ for $3 \mathrm{~h}$ and pretreated with a saturated solution of sodium chloride in methanol for the surface roughing to facilitate the uniform coating of the stationary phase on the inner wall surface. ${ }^{24}$ Briefly, a suspension of sodium chloride, which was obtained under stirring condition by addition of saturated sodium chloride solution in methanol into trichloromethane, was passed through the capillary column. After the solvent was expelled from the column, the column stayed at $200{ }^{\circ} \mathrm{C}$ for $3 \mathrm{~h}$ under nitrogen atmosphere. Then, the column was statically coated with the solution of GPCM in dichloromethane $\left(0.4 \mathrm{mg} \mathrm{mL} \mathrm{m}^{-1}\right)$ at $40^{\circ} \mathrm{C}$. One end of the column was sealed and the other end was connected to a vacuum system in order to gradually remove the solvent under vacuum. The coated column was then conditioned from $40^{\circ} \mathrm{C}$ to $180{ }^{\circ} \mathrm{C}$ at $1{ }^{\circ} \mathrm{C} \mathrm{min} \min ^{-1}$ and held at the high-end temperature for $7 \mathrm{~h}$ under a constant flow of nitrogen at $1 \mathrm{~mL} \mathrm{~min}^{-1}$.

\section{Results and discussion}

\subsection{Characteristic parameters and column efficiency}

The GPCM stationary phase was evaluated for its inherent thermal stability and polarity by TGA and McReynolds constants, respectively. As described in Fig. 1A, GPCM remains thermally stable up to $350{ }^{\circ} \mathrm{C}$, suggesting its good thermal stability as stationary phase for GC separations. Its McReynolds constants were determined at $120^{\circ} \mathrm{C}$ by the five probe compounds, namely benzene $\left(X^{\prime}\right)$, 1-butanol $\left(Y^{\prime}\right)$, 2-pentanone $\left(Z^{\prime}\right)$, pyridine $\left(S^{\prime}\right)$ and 1nitropropane $\left(U^{\prime}\right)$. Table 1 lists the general polarity and average polarity of the GPCM stationary phase as well as those of 5\% phenyl methylpolysiloxane stationary phase for comparison, suggesting the weak polarity of GPCM as the stationary phase for GC separations. In addition, it shows relatively larger $Y^{\prime}, U^{\prime}$ and $S^{\prime}$ values, suggesting its stronger H-bonding and dipole-dipole interactions with specific analytes. Moreover, its column efficiency was examined at different flow rates. Thus, the Golay curve of the GPCM capillary column, which relates the height equivalent to a theoretical plate (HETP) with flow rate, was determined by $n$-dodecane at $120^{\circ} \mathrm{C}$. As shown in Fig. $1 \mathrm{~B}$, it attained the minimum HETP of $0.311 \mathrm{~mm}$ at $0.40 \mathrm{~mL} \mathrm{~min}^{-1}$, corresponding to the column efficiency of 3210 plates per meter. In addition, the SEM images of the cross section and the inner coating of the GPCM capillary column are shown in Fig. 1C and D, respectively, showing the uniform coating of the GPCM stationary phase on the capillary column. The above results show that in comparison with the reported graphene and graphene oxide columns, ${ }^{18,19}$ the GPCM column achieved higher column efficiency mainly due to 

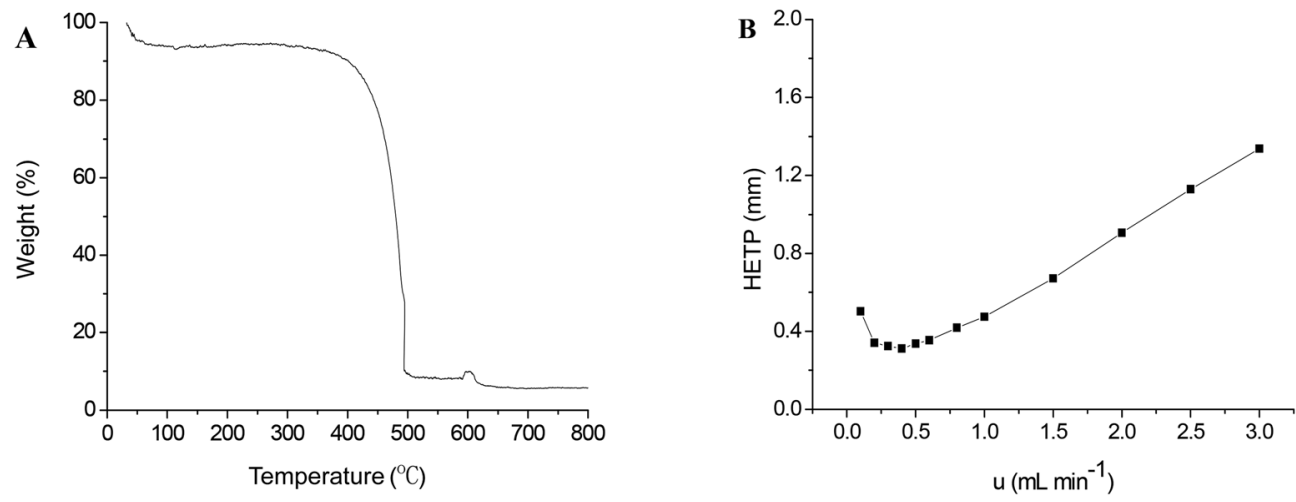

C

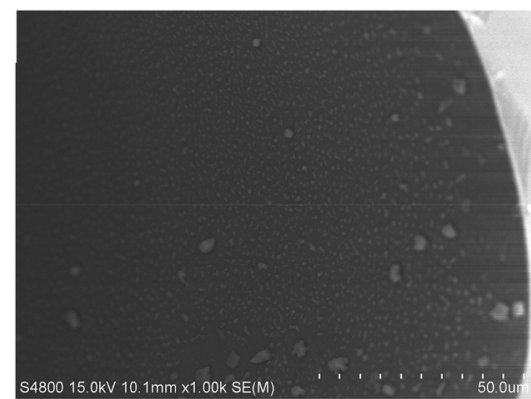

D

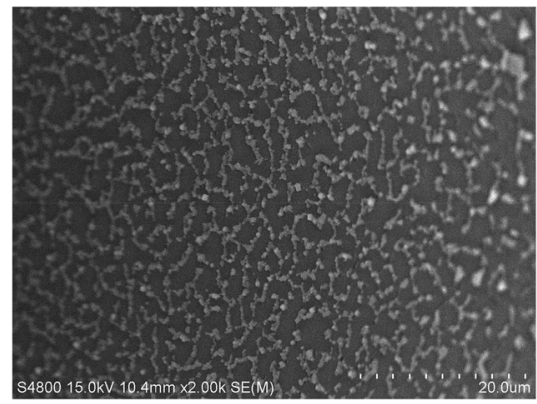

Fig. 1 (A) TGA curve of the GPCM stationary phase under nitrogen atmosphere; (B) Golay curve of the GPCM capillary column determined by $n$ dodecane at $120{ }^{\circ} \mathrm{C}$; (C) and (D) SEM images showing the cross section and the inner coating of the GPCM capillary column, respectively.

Table 1 McReynolds constants of the GPCM and HP-5MS capillary columns ${ }^{a}$

\begin{tabular}{llllllll}
\hline Stationary phase & $X^{\prime}$ & $Y^{\prime}$ & $Z^{\prime}$ & $U^{\prime}$ & $S^{\prime}$ & General polarity & Average polarity \\
\hline$I$ for GPCM & 707 & 743 & 715 & 793 & 841 & & \\
$I$ for squalane & 653 & 590 & 627 & 652 & 699 & 142 & 578 \\
$\Delta I$ for GPCM & 54 & 153 & 88 & 141 & 65 & 325 & 65
\end{tabular}

${ }^{a} X^{\prime}$, benzene; $Y^{\prime}$,1-butanol; $Z^{\prime}$, 2-pentanone; $U^{\prime}$, 1-nitropropane; $S^{\prime}$, pyridine. Temperature: $120{ }^{\circ} \mathrm{C}$.

the good dispersibility and uniform coating of the GPCM stationary phase on the inner wall of the capillary column.

\subsection{Separation of isomers of alkanes, alcohols and phenols}

Separation of linear and branched alkanes is of significant importance in petroleum industry ${ }^{25}$ and is also a challenging work, particularly for the branched isomers due to their similar physicochemical properties. On the basis of its unique structural features, we made investigations on the resolving capability of the GPCM column for alkane isomers. Fig. 2A and B show its isothermal separations of $\mathrm{C} 7$ and $\mathrm{C} 8$ alkane isomers, respectively, at $30^{\circ} \mathrm{C}$. The baseline separation of these isomers within short time demonstrates the high selectivity and resolving capability of the GPCM stationary phase for analytes of high resemblance. In addition, it can be noted that the more branched alkanes exhibited earlier elution. Its high capability for achieving the high resolution may result from the cooperative effect of pore size restriction and van der Waals interactions. The nanoporous structure may selectively retain the less branched analytes since the steric hindrance of highly branched molecules restrict their close contact with the graphite surface of GPCM, leading to the weaker interaction and shorter retention. ${ }^{26}$ Moreover, failing in close contact with the stationary phase also weakens their strength of van der Waals interactions with the phase.

Fig. $3 \mathrm{~A}-\mathrm{C}$ present the isomer separations of alcohols and phenols, respectively, on the GPCM column. For the polar butanol isomers in Fig. 3A, the GPCM column also exhibited nearly baseline separation, suggesting its high resolving ability for polar analytes. The noticeable tailing of the alcohols, especially the ones retained longer, may originate from the cooperative effect of their stronger H-bonding and dipole-dipole interactions with the stationary phase and the size selectivity of the porous structure. Also, the GPCM column achieved complete separation of the two unsaturated alcohol isomers, i.e., nerol and geraniol (Fig. 3B). Fig. 3C shows its high resolution for the phenol 

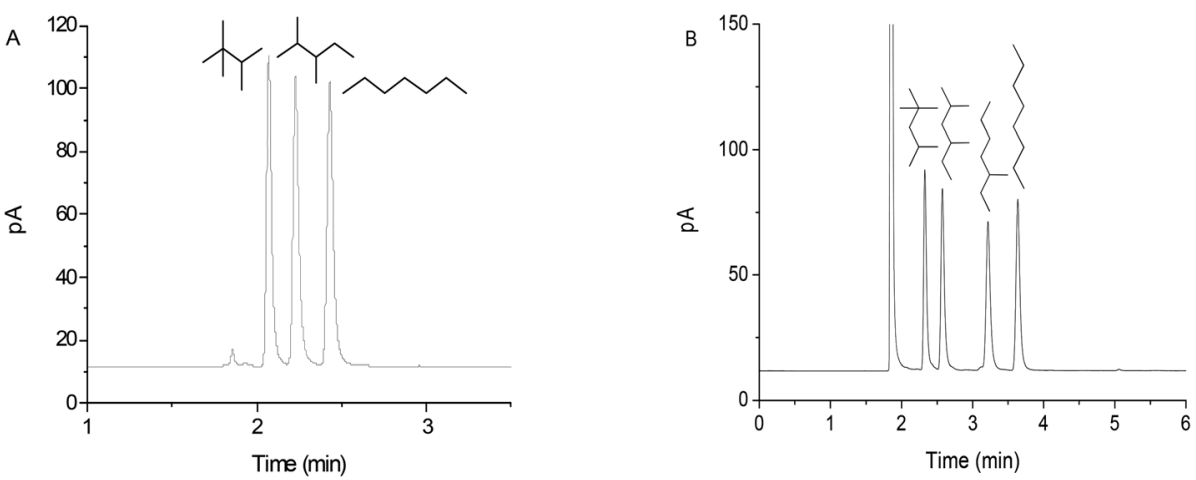

Fig. 2 Isothermal separations of (A) heptane isomers and (B) octane isomers at $30^{\circ} \mathrm{C}$ on the GPCM capillary column. Flow rate at $0.5 \mathrm{~mL}$ min ${ }^{-1}$ for (A) and at $1 \mathrm{~mL} \mathrm{~min}{ }^{-1}$ for (B).
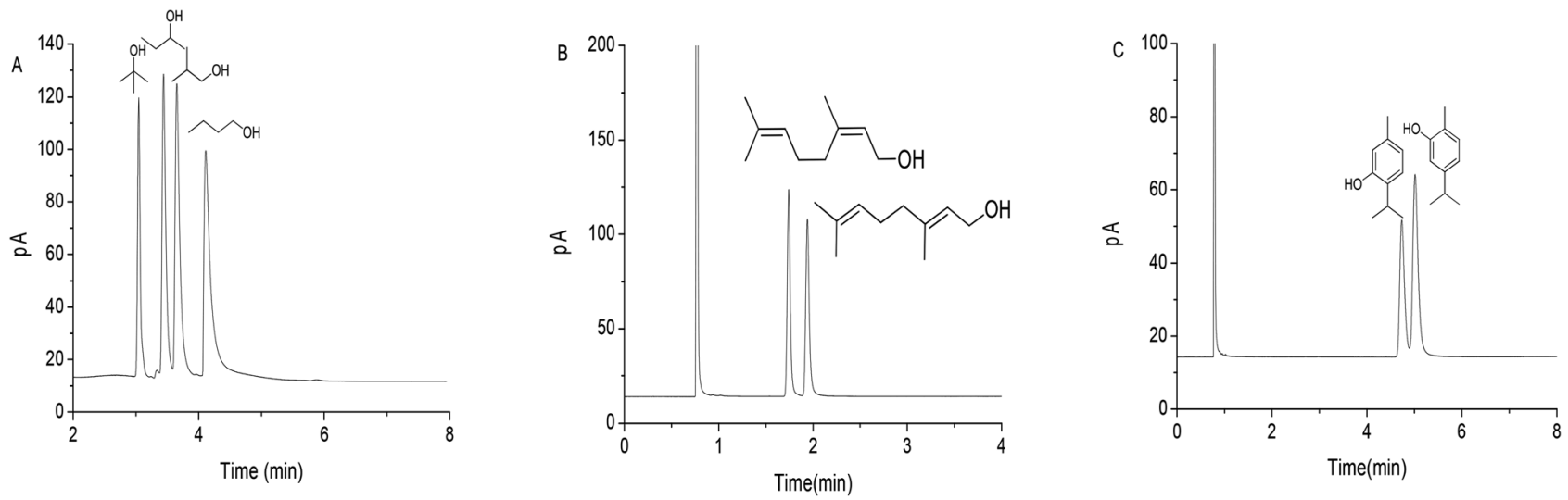

Fig. 3 Isothermal separations of alcohol and phenol isomers on the GPCM capillary column. (A) butanol isomers at $40^{\circ} \mathrm{C}$, (B) nerol and geraniol at $110^{\circ} \mathrm{C}$ and (C) musk phenol and carvacrol at $100{ }^{\circ} \mathrm{C}$. Flow rate at $0.3 \mathrm{~mL} \mathrm{~min}^{-1}$ for (A) and at $1 \mathrm{~mL} \mathrm{~min}^{-1}$ for (B) and (C).

isomers, musk phenol and carvacrol. The adjacent isopropyl to the phenol group in musk phenol sterically hinder its $\mathrm{H}$-bonding interaction with the stationary phase, leading to its earlier elution than its counterpart. The above results demonstrated the high selectivity and resolving ability of the GPCM column for nonpolar to polar analytes of high similarity, showing advantages over the graphene and graphene oxide columns ${ }^{18,19}$ owing to the cooperative effect of multiple molecular interactions and pore selectivity of the GPCM stationary phase. These results inspired us to further explore its separation performance for analytes of wide variety and its potential for separation of complex samples.

\subsection{Separation of a complex mixture of analytes of wide variety}

To comprehensively evaluate the separation performance of the GPCM column for analytes of diverse variety, a complex mixture consisting of 22 analytes of different types was employed. Meanwhile, a widely-used HP-5MS capillary column was used as reference for the evaluation. As shown in Fig. 4, the GPCM column achieved good resolution of all the analytes whereas the commercial column partially overlapped two analyte pairs, namely methyl octanoate/1,6-dichlorohexane (peaks 11/12, $R=$ 1.09) and ethyl benzoate/1,2,4-trichlorobenzene (peaks 13/14, $R$
$=0.68)$. Clearly, the GPCM stationary phase exhibits high resolving ability of halogenated analytes from esters, which may be attributed to the stronger dipole-dipole interaction and halogen-bonding interaction $(\mathrm{N} \cdots \mathrm{Cl}) \cdot{ }^{27,28}$ The cooperative effect of these interactions may enhance the distinguishing ability of the GPCM stationary phase for these analytes. Moreover, the GPCM stationary phase shows reversal elution sequence for three analyte pairs, namely cyclohexanone/1-hexanol (peaks 4/ 5), 1-bromononane/ $m$-nitrochlorobenzene (peaks 15/16) and $n$ tridecane/1-decanol (peaks 17/18). The later elution of the alcohols and halogenated analytes further evidence the different retention mechanism of the GPCM stationary phase from the polysiloxane phase. Specifically, the later elution of hexanol and decanol may be attributed to their stronger $\mathrm{H}^{-}$ bonding interaction $(\mathrm{O}-\mathrm{H} \cdots \mathrm{N})$ with the nitrogen atoms in different forms (pyridinic, pyrrolic and graphitic N) of the GPCM phase. In addition, the later elution of $m$-chloronitrobenzene than bromononane on the GPCM phase can be mainly ascribed to the comprehensive result of dipole-dipole, $\pi-\pi$ and halogen-bonding interactions. The above results demonstrated the high resolving capability and different retention mechanism of the GPCM stationary phase in contrast to the polysiloxane thanks to the cooperative contribution of its 

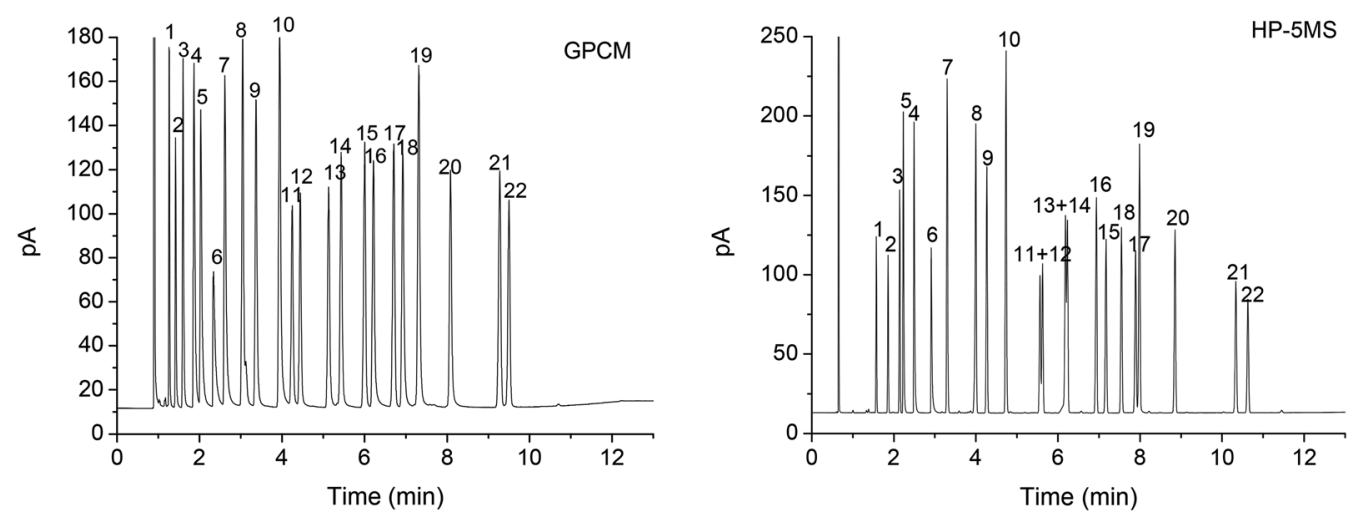

Fig. 4 Separations of the complex mixture consisting of analytes of different types on the GPCM and HP-5MS capillary columns. Peaks: (1) $n$ octane, (2) 1-bromopentane, (3) ethylbenzene, (4) cyclohexanone, (5) 1-hexanol, (6) 2,5-hexanedione, (7) benzaldehyde, (8) benzyl chloride, (9) o-dichlorobenzene, (10) acetophenone, (11) methyl octanoate, (12) 1,6-dichlorohexane, (13) ethyl benzoate, (14) 1,2,4-trichlorobenzene, (15) 1bromononane, (16) $m$-nitrochlorobenzene, (17) $n$-tridecane, (18) 1-decanol, (19) 1-methyl naphthalene, (20) biphenyl, (21) $n$-pentadecane and (22) methyl dodecanoate. Temperature program: $40^{\circ} \mathrm{C}$ for $1 \mathrm{~min}$ to $160^{\circ} \mathrm{C}$ at $10^{\circ} \mathrm{C} \mathrm{min}-1$. Flow rate at $1.0 \mathrm{~mL} \mathrm{~min}^{-1}$ for both of the columns.

Table 2 Repeatability and reproducibility of the GPCM capillary column on the retention times $\left(t_{R}\right.$, min) for separations of the indicated mixture $(n=4)$

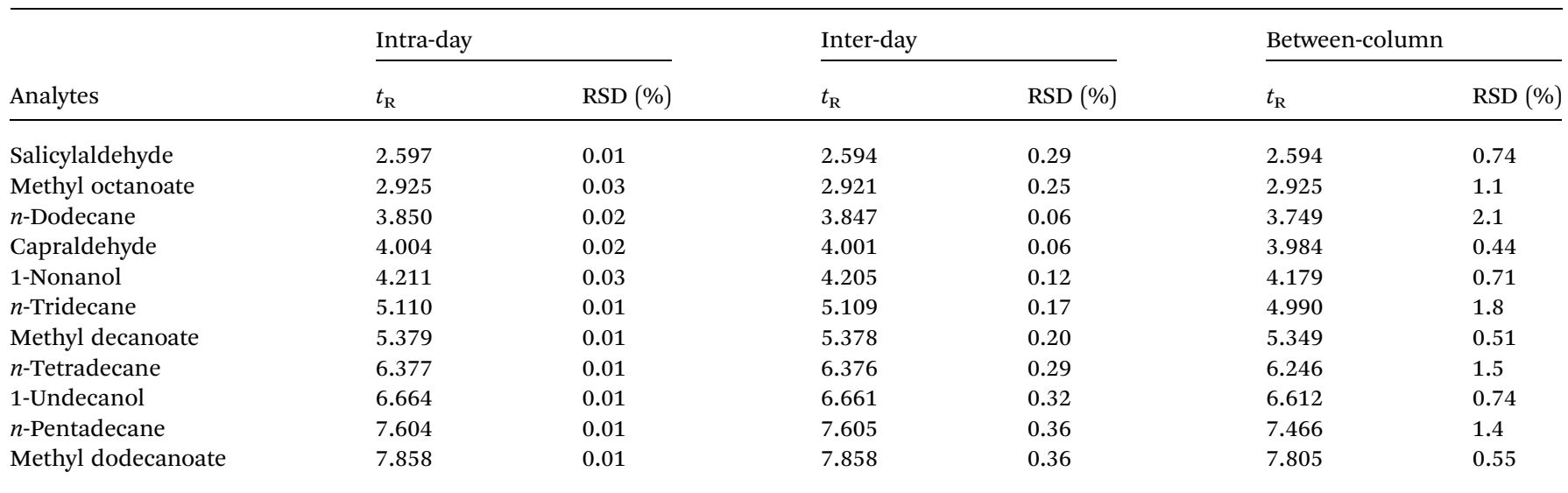

multiple types of molecular interactions with specific analytes, which may mainly involve $\mathrm{H}$-bonding, van der Waals, $\pi-\pi$ and halogen-bonding interactions as well as shape-fitting effect.

\subsection{Column repeatability and thermal stability}

For the GPCM columns, its column repeatability (intra-day, inter-day) and reproducibility (between-column) were investigated by separations of the indicated mixture and evaluated by relative standard deviation ( $\mathrm{RSD} \%$ ) on the analyte retention times. The obtained results are listed in Table 2, showing the RSD values of $0.01-0.03 \%$ for intra-day, $0.06-0.36 \%$ for inter-day and $0.44-2.1 \%$ for between-column, respectively. Notably, the column also achieved good reproducibility for aldehydes and alcohols that are sensitive to the column variations with the RSD values in the range of $0.44-0.74 \%$. The above results demonstrate its good column repeatability and reproducibility for diverse types of analytes.

Its column thermal stability was evaluated by separation of the indicated mixture after the column was conditioned from $40{ }^{\circ} \mathrm{C}$ up to each of the temperatures $\left(180-260{ }^{\circ} \mathrm{C}\right.$ in $20{ }^{\circ} \mathrm{C}$ increments) and held for $2 \mathrm{~h}$, respectively. As illustrated in
Fig. 5, over the range of conditioning temperature, the retention times remained almost unchanged for most of the analytes with RSD values in the range of $0.60-3.3 \%$. In addition, the selectivity 
Table 3 Effect of column conditioning temperatures on the selectivity factors of the analytes in the indicated mixture on the GPCM capillary column

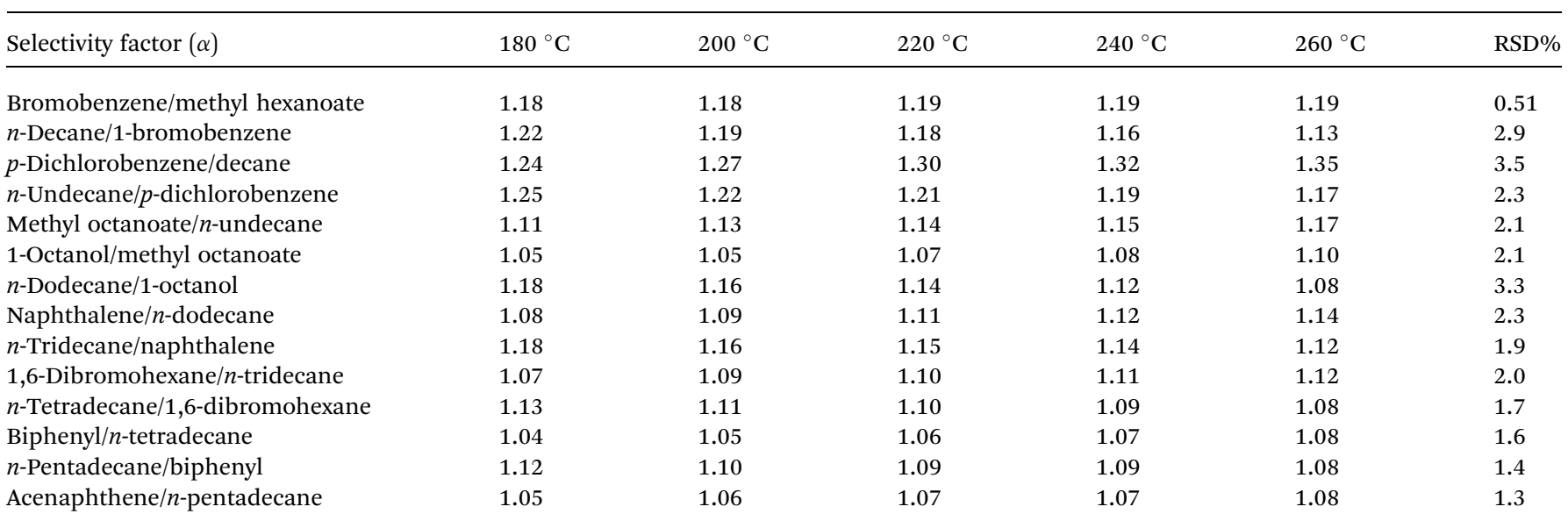

factors of the analytes over the temperature range are also provided in Table 3, indicating that the column maintained its high selectivity above 1.05 for all of the analytes with RSD values of $0.51-3.5 \%$. The above results demonstrated the good thermal stability of the GPCM column.

\section{Conclusions}

This work describes the separation performance of the GPCM stationary phase for GC separations, showing high selectivity and resolving capability for nonpolar to polar isomers (alkanes, alcohols and phenols) and general analytes of diverse variety. Compared with the widely-used HP-5MS column, the GPCM column shows high resolution and different elution order for certain analytes. Particularly, it delayed the elution of alcohols and halogenated analytes probably due to its stronger $\mathrm{H}^{-}$ bonding and halogen-bonding interactions with these analytes. Besides, the GPCM column also exhibited good separation for a wide range of analytes thanks to its multiple molecular interactions and size selectivity. It achieves high selectivity for different types of analytes through its unique interactions with specific analytes. This work demonstrates the promising future of the graphene-based porous carbon material in chromatographic separations and may also interest more researchers in utilizing porous carbon materials in separation science.

\section{Acknowledgements}

The authors are grateful for the financial support by the National Natural Science Foundation of China (21575013) and the 111 Project B07012 in China.

\section{References}

1 C. D. Li, Z. J. Li and S. Dai, Angew. Chem., Int. Ed., 2008, 47, 3696-3717.

2 P. F. Zhang, H. Y. Zhu and S. Dai, ChemCatChem, 2015, 7, 2788-2805.
3 C. West, C. Elfakir and M. Lafosse, J. Chromatogr. A, 2010, 1217, 3201-3216.

4 Y. Zhao, S. S. W. Szeto, R. P. W. Kong, C. H. Law, G. Li, Q. Quan, Z. J. Zhang, Y. Q. Wang and I. K. Chu, Anal. Chem., 2014, 86, 12172-12179.

5 J. J. Li, R. J. Lu, B. J. Dou, C. Y. Ma, Q. H. Hu, Y. Liang, F. Wu, S. Z. Qiao and Z. P. Hao, Environ. Sci. Technol., 2012, 46, 12648-12654.

6 L. Chen, T. Ji, L. Brisbin and J. H. Zhu, ACS Appl. Mater. Interfaces, 2015, 7, 12230-12237.

7 X. F. Bing, Y. J. Wei, M. Wang, S. Xu, D. H. Long, J. T. Wang, W. M. Qiao and L. C. Ling, J. Colloid Interface Sci., 2017, 488, 207-217.

8 B. Liu, H. Shioyama, T. Akita and Q. Xu, J. Am. Chem. Soc., 2008, 130, 5390-5391.

9 B. Liu, H. Shioyama, H. Jiang, X. Zhang and Q. Xu, Carbon, 2010, 48, 456-463.

10 L. Radhakrishnan, J. Reboul, S. Furukawa, P. Srinivasu, S. Kitagawa and Y. Yamauchi, Chem. Mater., 2011, 23, 1225-1231.

11 H. Jiang, B. Liu, Y. Lan, K. Kuratani, T. Akita and H. Shioyama, J. Am. Chem. Soc., 2011, 133, 11854-11857.

12 C. X. Li, C. G. Hu, Y. Zhao, L. Song, J. Zhang, R. D. Huang and L. T. Qu, Carbon, 2014, 78, 231-242.

13 H. X. Zhong, J. Wang, Y. W. Zhang, W. L. Xu, W. Xing, D. Xu, Y. F. Zhang and X. B. Zhang, Angew. Chem., Int. Ed., 2014, 53, 14235-14239.

14 Q. Liu, J. B. Shi and G. B. Jiang, Trends Anal. Chem., 2012, 37, 1-11.

15 J. Fan, Z. L. Dong, M. L. Qi, R. N. Fu and L. T. Qu, J. Chromatogr. A, 2013, 1320, 27-32.

16 X. Wang, B. Liu, Q. P. Lu and Q. S. Qu, J. Chromatogr. A, 2014, 1362, 1-15.

17 H. Amanzadeh, Y. Yamini, M. Moradi and Y. A. Asl, J. Chromatogr. A, 2016, 1465, 38-46.

18 Y. Feng, C. G. Hu, M. L. Qi, R. N. Fu and L. T. Qu, Chin. Chem. Lett., 2015, 26, 47-49.

19 J. Fan, M. L. Qi, R. N. Fu and L. T. Qu, J. Chromatogr. A, 2015, 1399, 74-79. 
20 N. Han, M. Y. Ye, M. L. Qi, R. N. Fu and L. T. Qu, $R S C A d v$., 2015, 5, 74040-74045.

21 X. H. Yang, C. X. Li, M. L. Qi and L. T. Qu, J. Chromatogr. A, 2016, 1460, 173-180.

22 X. Q. Zhang, S. Chen, Q. Han and M. Y. Ding, J. Chromatogr. A, 2013, 1307, 135-143.

23 X. J. Liang, X. S. Wang, H. X. Ren, S. X. Jiang, L. C. Wang and S. J. Liu, J. Sep. Sci., 2014, 37, 1371-1379.
24 A. J. Huang, N. Nan, M. Chen, X. Pu, H. Tang and Y. L. Shun, Acta Sci. Nat. Univ. Pekin., 1988, 24, 425-429.

25 Z. R. Herm, E. D. Bloch and J. R. Long, Chem. Mater., 2014, 26, 323-338.

26 J. L. Gundersen, J. Chromatogr. A, 2001, 914, 161-166.

27 S. H. Jungbauer, D. Bulfield, F. Kniep, C. W. Lehmann, E. Herdtweck and S. M. Huber, J. Am. Chem. Soc., 2014, 136, 16740-16743.

28 M. H. Kolář and P. Hobza, Chem. Rev., 2016, 116, 5155-5187. 